\title{
SITUAÇÕES DE VIDA E MORTE - UMA QUESTÃO REFLEXIVA *
}

\author{
Célia Caldcira F. Kestemberg** \\ Denise de Assis C. Sória (Relatora)*** \\ Elizabcth Ferreira Pires Paulo****
}

\begin{abstract}
RESUMO - O presente trabalho trata do estudo bibliográfico acerca das questões que envolvem a situação vida e morte. Procurou-se pautar em literatura que abrangesse os aspectos sócio- antropológicos, filosóficos, psicológicos e biológicos acerca do tema em questão. Ainda aborda a reação da equipe de enfermagem frente à morte. O objetivo é suscitar a reflexão crítica acerca deste fenômeno inexoravelmente humano.
\end{abstract}

ABSTRACT - The present study refers to the bibliographic search about questions that involve the situation of life and death. It was tried to be put in literature that included social-anthropological, philosophical, psychological and biological aspects conceming to the topic in question. Yet broaches the reaction of the nursing team towards death. Its objective is to suggest the critical reflection of this inexorably human phenomenon.

\section{INTRODUÇÃO}

A morte é algo desconhecido c o homem desde sempre a abominou c sempre a abominarí. Scgundo $\mathrm{ROSS}^{10}$. é impossível ao homem pensar. imaginar um fim real de sua própria vida. Nosso inconsciente não accita a mortc como algo natural que fa\% parte do próprio cxistir.

$\operatorname{ROSS}^{10}$ afirma que a morte $\mathrm{cm}$ si cstá associada a uma ação má. a algo que chama por recompensa ou castigo tanto para quem foi como para quem fica. As pessoas se afligem. choram, rasgam as vestes. deixam de comer numa tentativa de auto-punição para cortar ou reduzir o castigo csperado pela culpa assumida pela morte do ente querido. Dentro de cada pessoa que perde alguém. fica um sentimento antagônico de raiva e adoração. É como a criança ao perder a mãc: cla embora ame intensamente sua mãc, $1 \mathrm{~cm}$ raiva porque csta a deivou só.

Muitas culturas possucm rituais para cuidar dos mortos que se associam a este sentimento de raiva latente $\mathrm{cm}$ todos os homens. embora jamais seja admitido. A exemplo disto os índios americanos atiravam flechas para afugentar o espírito mau: a salva de tiros num funcral militar pode cstar associada a csta mesma idćia.
Na realidade, o homem praticamente não mudou. continua a mortc sendo um medo universal, o que mudou foi o scu modo de lidar c conviver com a mortc, com o morrer.

Obsena-se que com o avanço da ciência, da tecnologia. a morte pode ser até retardada. Era de se pensar também que o homem tivesse, pelo seu alto grau de cmancipação, descobcrto meios que proporcionassem maior preparo às pessoas para se haverem com tal fenômeno. entretanto. não ć isto que se nos apresenta. Ao contrário, a monte continua sendo um tabú. os cufemismos permanecem, a dúvida $\mathrm{cm}$ relação a dìcr ou não a verdade ao paciente continua.

Outrora. o indivíduo na fase terminal cra cercado de toda a família c amigos dos quais ele se despedia, na certěa ou não de um dia se reencontrarem. A morte cra tristc. ć verdadc. Os tempos mudaram. Atualmentc. o paciente terminal quase sempre. encontra-se sozinho. distante dos seus entes queridos, num leito de hospital, aguardando a hora final. A mortc tra $z \mathrm{~cm}$ si um sentimento de tristera peculiar. Compreende-se que atualmente cla é mais triste. é muito solitária, mecânica, desumana. Às večcs ć difícil ao profissional de saúde determinar tecnicamente a hora cxata $\mathrm{cm}$ que o paciente morreu.

\footnotetext{
* Tema livre do $43^{\circ}$ CBEn - Curitiba - PR

** Docente da I Iniversidade Estadual do Rio de Janeiro - UIERJ

*** Docente da (iniversidade do Rio de Janeiro - (INI-RIO)

**** Docente da I nniversidade Federal do Rio Grande do Norte - ITRRN
} 
Cabc. cntão. o seguintc questionanento: aonde está ' lcı ando o homem. todo cssc avanço tecnológico"

\section{Parafrascando BERTHOLD BRECHT:}

"Sc a ciência não for para tornar o homcm mais fcliz, cntão não ć ciência".

Objetivando repensar. refletir acerca deste fenômeno inalicnável do homem - a mortc - o gnupo claborou cstc trabalho. Scrão abordados os aspectos biológicos. antropológicos, filosóficos e psicológicos accrca da montc. bem como a reação da cquipe de enfermagem frentc à mesma.

\section{ABORDAGEM SÓCIO-ANTROPOLÓGICA}

A mortc. cmbora rechaçada como tabú na vida cotidiana. cstá presentc $\mathrm{cm}$ todos os momentos. nas mitologias. nos rituais. na profundidade de cada um de nós.

Pcrcebc-sc que há uma cxaltação da mortc nos mcios de comunicação. vê-sc nos jornais. revistas. tclcrisão. cadáveres no chão. cmpilhados. desfigurados. Entrctanto. há uma dissimulação silenciosa na vida cotidiana $\mathrm{cm}$ que cla ć banida das conversas. obscurecida por metáforas c cscondida das crianças.

Scgundo RODRIGUES ". a mortc guarda $\mathrm{cm}$ si um conjunto de forças sobrenaturais proveniente dos espíritos que operam num objeto ou numa pessoa. Basta olhar $\mathrm{cm}$ volta dos muros dos cemitcrios para ver a quantidade de ritos mágicos de que cla ć objeto. Ritos que cxprimem o seu poder temivel. Entre os Pigmeus. a iniciação dos magos crigc provas para o ingresso na socicdade secrela dedicada à magia negra. muitas delas ligadas ao contato com a mortc c com a impurcza. RODRIGUES" cita um trabalho fcito por DA VID SUDNOW acerca da mortc. onde afirma que nos hospitais cxistc um estigma que recai sobre os indivíduos que se relacionam com cadáicres. A presença delcs $\mathrm{cm}$ algum lugar do hospital associa-sc à ocorrência de mortc. Estes individuos. "papa defuntos". guardam $\mathrm{cm}$ si a magia da mortc. São cles considerados culturalmentc de menor status. pois a manipulação de corpos mortos ć considerado um trabalho de menor dignidade. Esscs individuos são visıos como poluidos por causa de suas atividades e cspiritualmente são considerados como possuidores de fluidos negativos.

A morte para a consciência colctiva representa um afastamento do individuo da convivência humana. Esta cxclusão. cntrctanto. $1 \mathrm{~cm}$ um caríter temporárı c tem por cfeito fazer com que o morto passe da socicdadc palpável dos vivos para a socicdadc invisivel dos ancestrais. Nessa passagem. de um mundo a outro, do conhecido ao desconhecido. o individuo recebc um acondicionamento que se concreti/a $\mathrm{cm}$ ritos que o preparam pam a nova vida. Nesta fase de preparo. fasc intermediária. cntre a desintegração do individuo crcluido de um mundo c sua intcgração no outro mundo. dos mortos. acredita-sc que cxistam forças ncfastas irradiadas pela mortc. forças nocis as que amcaçam o homem. Assim scndo. a socicdade deverá se prevenir c se munir de recursos simbólicos capazcs de altcrar cssas forças c neutralizi-las. Explicam-sc assim. as práticas funcrais que guardam $\mathrm{cm}$ si grande valor cxpressivo. pois o corpo morto não pode scr despre/ado. ć necessário dar-lhe uma sepultura nào por questòcs higiênicas. como scria cxplicado talı c\% pela microbiologia. mas por obrigaçio moral O cnterro c as outras formas de se lidar com o corpo morlo. ć um meio de a comunidade assegurar a seus membros que o individuo morto caminha na direçio de ocupação do scu lugar detcrminado: der idamente sob controlc. Estas práticas comunicam ao gnupo uma mensagem que crolui da insegurança ao sentimento de ordem. c representam a mancira especial que cada gnipo tem de resolver o mesmo problema fundamental: o drama da finitude humana.

A mortc quebra o curso normal das coisas $c$ questiona as bases morais da socicdadc. amcaçando a cocsão c a solidaricdade do gnıpo fcrido $\mathrm{cm}$ sula intcgridade. A reação do homem à morte ć um impulso contrírio a cssas forças desagregadoras. Os cfeitos da mortc não se restringem portanto a dar fim a cristência matcrial do homem. Ela atinge dirctamente o capital inrestido nesse corpo pelo gnupo social Quando um homem morrc. não ć apenas uma fraçĩo do gnupo que foi roubada. algo de dignidade infinitamentc mais cler ada foi afctado - a própria estrutura social. Com isto o cdifício social corre o risco de desmoronar-se. Os individuos. com a morte de um de scus membros. aproximam-sc mais. ma tentativa de ocupar o lugar vazio c restabelecer a intcgridade Estas considerações. nos levam a cntender que o sentimento que a morte determina. varia com o tipo de morte c o significado do morto. De que motreu Morte natural"? Acidẹtıl Quem mợrcu") Que espaço no gnupo social ocupava csla peșsoa") Por (jue morreu"

Cada socicdade dáa mortc a sua resposta A mortc do corpo é a mortc do simbolo da cstrutura social. é a cridência da intropia. ć a imposição ao homem "de se pensar na finitude". 
RODRIGUES ${ }^{9}$ apresenta um outro aspecto curioso a respeito da morte. O homem procura dar ao cadáver, aparência de vida; banhando-o, barbeando-0, vestindo-o, enfim, dando-lhe uma boa aparência. As flores que são lançadas à sepultura estão também presentes em outros ritos ligados à vida (casamento, aniversário, nascimento, etc.).

Na verdade, o que se teme da morte é exatamente o que ela tem de morte, e o que nela se cultua é o amor à vida.

\section{ABORDAGEM FILOSÓFICA}

"Assim que o homem começa a viver, tem a idade suficiente para morrer".

\section{Martin Heidegger}

O que é a morte? Seria a morte o fim da vida, o fim do homem?

Todo homem, de uma maneira ou de outra, reflete sobre estas questões.

Quando o homem contempla a sua limitação, afirma Heidegger, é que se conscientiza que é finito. que está num horizonte de tempo. Esse tempo iniciase com o nascimento e termina com a morte.

A clara e constante consciência da condição de mortal percebe que não tem o direito de desperdiçar o pouco tempo que dispõe a sua cxistência; que cada instante é irreparável e que, por isso mesmo, deve ser aproveitado o mais plenamente possível.

Ao conscientizar-se da possibilidade imediata de sua própria morte. o homem é levado a rever as prioridades e os valores de sua existência, relativando o que até então era absoluto. Nossa consciência, entretanto. segundo ROSS ${ }^{10}$, abomina esta idéia de mortc real. é inconcebível para o homem aceitar tranquilamente o fim de sua existência aqui na Terra.

Nossa primeira experiência com o fenômeno da morte, acontece através da morte dos outros. Ampliamos nossa consciência de morte $\mathrm{cm}$ vários momentos durante a nossa existência. O morrer dos outros coloca-se diante do extraordinário fenômeno da transformação de vida em não vida. Aquele que morre deixa o mundo, entretanto apenas como ser, apenas fisicamente, visto que aqueles que permanecem ainda cstão com ele. O corpo perece, mas as idéias ficam e por vezes perpetuam-se.

Nessa abordagem filosófica, BOEMER ${ }^{3}$ afirma que a morte é uma realidade no mundo, é um fenômeno da vida. Morte é uma experiência inalienável de cada um de nós; morte é essencialmente minha, de tal forma que ninguém pode me representar nesse episódio de minha experiência; é algo que cada um de nós precisa assumir num determinado tempo. Morrer não é um acontecimento, mas um fenômeno que precisa ser compreendido "existencialmente".

\section{ABORDAGEM BIOLÓGICA}

De acordo com BRUNNER \& SUDDARTH ${ }^{4}$, "a doença é uma expressão dinâmica, em constante mudança de equilíbrio entre a lesão da célula ou atividade celular anormal e os mecanismos de defesa ou de compensação do corpo". Um indivíduo adoece gravemente quando um órgão importante de homeostase estiver comprometido. Quando o meio interno está substancialmente mudado, teremos todas as células lesadas ou mortas. Então, a morte é geralmente definida como uma cessação da atividade do coração e dos pulmões, considerados os principais órgãos da homeostase. Mais recentemente a indicação de morte passou a ser considerada como a ausência de função cercbral através do eletroencefalograma.

Já Du GAS apud GUIMARÃES et al. ${ }^{5}$, diz que o paciente gravemente enfermo, à medida que enfraquece, vai fracassando seus mecanismos homeostáti$\cos \mathrm{e}$ apresenta as seguintes mudanças:

- perda do tônus muscular;

- interrupção progressiva do peristaltismo;

- circulação lenta:

- respiração difícil;

- perda dos sentidos;

Para TODOLI apud GUIMARÃES et al ${ }^{7}$, a morte é descrita como sendo um processo com os seguintes estágios:

- parada cardíaca: morte clínica:

- parada neurológica: perda dos reflexos e da sensibilidade:

- parada dos centros bubulares: morte real;

- autólise dos tecidos: morte biológica.

O ponto fundamental neste processo é a parada cardíaca. Em decorrência da mesma ocorrem as demais paradas, inclusive a cerebral.

Mas, com os transplantes cardíacos, há uma mudança quanto à definição de morte $\mathrm{c} o$ estabelecimento do momento de sua presença. O momento da morte deixa de ser definido a partir da parada cardíaca $\mathrm{e}$ passa a sê-lo tendo como ponto de referência a atividade cerebral. Então, uma pessoa é considerada morta 
clinicamente quando nela houver uma degeneração da massa ccrebral. KAUFFER et al. apud GELAIN ${ }^{6}$, dizem "ao prevalecer como critério a perda da função do cérebro em lugar do coração, existe atualmente unanimidade em determinar o momento da morte quando se der a parada das atividades cerebrais. A respeito, considera-se decisiva a comprovação indubitável da perda irreversível de todas as funções cerebrais antes de se certificar o falecimento no caso de morte cerebral".

Os seguintes critérios foram apresentados por um grupo de juristas, clérigos e cirurgiões reunidos em Londres, em 1966, para aceitar-se o estabclecimento do momento da morte a partir da perda irreversível da totalidade funcional do cérebro:

- dilatação completa da pupila sem nenhuma resposta reflexa à luz;

- ausência total de respiração espontânea depois que o respirador mecânico cessou por cinco minutos;

- queda contínua da pressão sanguínea apesar das doses maciças de drogas vasopressoras;

- traçado do eletroencefalograma pleno durante vários minutos.

Então, o homem é considerado clinicamente morto, diante da morte irreversível do cércbro, mesmo que o coração continue pulsando, podendo-se então falar em "vida biológica" de alguém clinicamente morto.

Para a enfermeira, é importante o conhecimento científico da situação de morte do paciente, os aspectos fisiopatológicos. Alguns sinais são indicativos de morte eminente. Os reflexos do paciente gradativamente vão desaparecendo e ele torna-se incapaz de se mover. Quanto a sua respiração, também torna-se, pouco a pouco, dificil. Sua face passa a ter um tom cianótico. Já a epiderme apresenta-se fria e pegajosa e o pulso acelera-se e enfraquece. As pupilas dilatamse com o aumento da anoxia. Ocorre queda da pressão sanguínea, elevação da temperatura e da frequiência respiratória.

\section{ABORDAGEM PSICOLÓGICA}

De acordo com KUBLER-ROSS ${ }^{10}$ o paciente terminal tem experiências emocionais desde o momento em que toma conhecimento da gravidade de sua doença. A autora identifica cinco (5) estágios que antecedem a fase terminal:

- negação

- ira
- barganha

- depressão

- aceitação

Primeiro Estágio: Negação

A maioria dos pacientes moribundos reagem ao conhecimento de sua doença fatal: "Não, não eu, não pode ser". A partir da negação da situação, ele passa então a desacreditar do médico, laboratório, hospital e funcionários. Sendo assim, procura outras instituições de saúde, outros laboratórios, outros profissionais, na esperança de provar que não é verdade o que está acontecendo com ele.

A negação, logo após à apresentação de um diagnóstico, é mais comum no paciente que é informado bruscamente ou prematuramente por alguém que não conhece bem o paciente, sem levar em consideração o preparo e disposição do mesmo. Normalmente, a negação é uma defesa provisória, pois pode ser substituída por aceitação parcial. Alguns pacientes sustentam a negação até o final.

Grande parte dos pacientes não faz uso da negação tão prolongadamente. Tais pessoas podem discutir rapidamente a respeito da realidade de sua situação, contudo, de repente, demonstram sua incapacidade de enfrentar essa situação verdadeiramente.

A necessidade de negação existe em todo paciente, casualmente no início de uma doença grave, muito mais do que próximo do fim da vida. Mais tarde a necessidade de negação aparece e desaparece e o paciente usa mais isolamento do que negação.

Enfim, a primeira reação do paciente pode ser um estado provisório de choque, do qual ele se recupera gradualmente, dependendo de como recebe a notícia da doença fatal, de seu preparo durante a sua vida para lidar com tal situação.

\section{Segundo Estágio: Ira}

A partir do momento em que o estágio de negação não mais pode ser mantido, é substituído por sentimentos de ira, revolta, inveja e ressentimento. A pergunta será: por que eu? O paciente agride a instituição, a equipe de saúde e até os próprios familiares.

Ao contrário do estágio de negação, este é muito difícil de lidar, do ponto de vista da família e pessoal hospitalar, pois a ira é distribuída em todas as direções e projetada sobre o ambiente, às vezes quase sem fundamento. 


\section{Terceiro Estágio: Barganha}

O paciente na fase terminal usa a barganha como uma tentativa de prolongar a vida. Ele acredita que possa ser recompensado por bom comportamento e quase sempre seu desejo é um prolongamento da vida ou então, alguns dias sem dor ou desconforto.

Na realidade, a barganha é uma busca, que visa adiar um acontecimento inevitável, tem que incluir um prêmio of erecido "por bom comportamento".

A maioria das barganhas são feitas com Deus e geralmente são mantidas em segredo ou reveladas ao capelão.

Psicologicamente, promessas geralmente não cumpridas podem estar associadas com silenciosa culpa e, seria, portanto, importante que os profissionais juntamente com o capelão, trabalhassem tais afirmações do paciente até que o mesmo ficasse livre de todos os temores que o perturbam.

\section{Quarto Estágio: Depressão}

Este estágio caracteriza-se por uma intensa queda de ânimo, influenciando em todas as atividades do paciente, que passa a se recusar a colaborar com o tratamento $\mathrm{c}$ frequentemente se fecha no silêncio.

A equipe de saúde, juntamente com o capelão, podem ser de grande ajuda durante essa fase, na tentativa de aceitação do seu estado de saúde irreversível. Cabe deixá-lo expressar seu pensar, pois facilita a aceitação final mais facilmente. Às vezes é dispensável a interação verbal, basta ouví-lo, tocá-lo carinhosamente com a mão, ou apenas sentar ao seu lado.

A família, seus parentes mais próximos e seus amigos exercem importante papel nesta fase, quando o paciente pode compartilhar com os mesmos suas angústias e ansiedades.

Apenas os pacientes que são capazes de atingir este estágio e superá-lo conseguem morrer em estágio de aceitação e paz. Para isto, devem dominar suas angústias e ansiedades.

\section{Quinto Estágio: Aceitação}

Neste estágio, o paciente passa a accitar sua situação. Ele deixa de agredir, de irritar-se e concentra-se em si. Mas, esta aceitação, às vezes, é aparente e passa a ser uma forma de agressividade ou depressão.

O acompanhanento da dinâmica psicológica do paciente é algo muito importante.

Este é um período crítico para a família, que geralmente necessita de mais ajuda, compreensão e apoio. Quando o paciente moribundo consegue uma certa paz e aceitação, seu círculo de interesse diminui. Ele prefere ficar só, sem interessar-se por novidades e problemas do mundo exterior. As visitas começas a incomodá-lo, falta disposição para conversar. Ele geralmente solicita a diminuição de visitantes. As comunicações tomam-se não verbais, podendo ser apenas através de um segurar de mão, olhar ficar sentado em silêncio junto dele, enfim, a presença de alguém junto a ele, pode confirmar que não estará sozinho até o final.

Essas fases, na verdade, segundo KUBLER$\operatorname{ROSS}^{10}$, não ocorrem numa seqüência lógica, mas numa dinâmica muito grande. Por vezes, um estágio sobrepõe o outro ou mesmo da fase de aceitação, o paciente volta às anteriores. Cabe ressaltar ainda que em todos os estágios pode haver a presença de um sentimento muito forte no homem: a esperança. $\mathrm{O}$ paciente acredita, por vezes, em sua cura ou na existência de um erro de diagnóstico. Daí acrescenta-se a importância da assistência individualizada. Cada pacientc reage de uma forma, a experiência da terminalidade é única para cada pessoa.

\section{A FAMILIA DO PACIENTE}

Se não é valorizada a situação da família do paciente em fase terminal, não se pode ajudá-lo com eficácia. No período da doença, os familiares desempenham papel importante, e suas reações muito contribuem para a própria reação do paciente.

A doença grave de um membro da família com conseqüente hospitalização, pode causar mudanças radicais no lar, as quais a família terá que se adaptar. Se o paciente for o esposo, a mulher terá que desempenhar funções do marido mais as suas; isto poderá causar-lhe insegurança e nervosismo. Se o paciente for a esposa, o marido terá que participar mais amiúde dos problemas do lar. Conscientemente ou não, poderá ressentir-se de tais mudanças, apesar de entender bem a situação.

Esses familiares terão que receber ajuda da equipe de saúde para poderem extravasar seus sentimentos. Deve-se deixar o parente do paciente falar, chorar ou gritar, se necessário. Deve-se deixar que ele participe, converse, questione. O enfermeiro deve estar sempre presente e tentar compreender as necessidades dos familiares e ajudá-los com uma orientação construtiva. A ajuda mais significativa que o enfermeiro pode dar a qualquer parente, é partilhar com eles seus 
sentimentos antes que o paciente morra.

KUBLER-ROSS ${ }^{10}$ afirma que os membros da família experimentam diferentes estágios de adaptação, semelhantes aos descritos com referência aos pacientes. A princípio, muitos deles não podem acreditar que seja verdade. Pode serque neguem o fato de que haja tal doença na família ou "comecem a andar" de médico em médico, na vã esperança de ouvir que houve erro no diagnóstico. Portanto, a família sofre certas mudanças, dependendo muito da habilidade com que se comunica o fato. Se cada um tenta manter segredo em relação ao outro, criarão uma barreira artificial entre si, que dificultará qualquer preparação para o pesar futuro, tanto do paciente quanto de sua família. O resultado final será muito mais dramático do que para aqueles que podem, às vezes, conversar e chorar juntos.

Quando o paciente atravessar o estágio da ira e de ${ }^{\circ}$ raiva, a enfemeira deve apoiar a família e ajudar ao paciente a chegar ao estágio de aceitação. Deve também fazer com que os familiares entendam que os pacientes que aceitam a morte são mais capazes de desapegar da vida lentamente e em paz, e assim morrer com dignidade e tranqüilidade.

\section{O MORRER E A EQUIPE DE ENFERMAGEM}

Diversos autores consideram a morte como parte integrante da vida, tão natural e previsível como o nascer. Porém afirmam que as enfermeiras não estão preparadas para auxiliar seus pacientes neste momento difícil.

GUIMARÃES 7 observou o comportamento de algumas enfermeiras e constatou duas atitudes: a fuga, em que o paciente é mantido à distância e praticamente isolado, ou, a negação, onde é dito ao paciente "você vai melhorar logo", e o assunto é esquecido.

Ressalta ainda a mesma autora, que raríssimas são as vezes onde constatamos uma atitude mais afetiva, relevada e descontraída, que af aga o doente com as mãos e com palavras que o faz sentir gente e, mesmo no hospital, entre amigos. Amigos esses que se preciso for, podem conversar com ele, com tranqüilidade, nunca com indiferença, sobre a sua possibilidade de morte, e ficar um pouco junto, e lhe dar talvez um pouco de paz.

É necessário que o paciente tenha o enfermeiro mais perto de si, e que a muralha que o conhecimento científico impõe se rompa e o paciente possa chegar até o enfermeiro. É preciso que haja uma relação mais humana.

É imprescindível que não se esqueça que o paciente é um ser humano que ainda não perdeu seus direitos, e como tal deve ser ouvido, consultado. Portanto, ele deve decidir, se consciente, sobre sua hospitalização. Ele tem o direito de escolher se prefere morrer no ambiente familiar ou em um hospital.

BOEMER $^{3}$ diz que uma vez declarado o estado de terminalidade, os pacientes ficam muito sós, queixam-se que o médico não vai mais ao seu quarto, a extensão da prescrição médica aumenta e tende a tornar-se repetitiva, atendo-se mais aos cuidados gerais c dieta, no sentido de manutenção biológica dos pacientes.

As evoluções de enf ermagem também são repetitivas, e só se referem aos aspectos técnicos do cuidado prestado e às funções fisiológicas do indivíduo. Traduzindo, portanto, o caráter funcionalista da instituição.

Urge a necessidade de se mudar a filosofia dos serviços, e se tentar uma proposta de aproximação a esses pacientes, pois é no período de preparação para a morte que o papel do enfermeiro assume significação.

O que se percebe atualmente, é que as enfermeiras fogem dos pacientes moribundos, só se aproximam para prestar cuidado e depois desaparecem. No entanto, quando o paciente morre, fica rodeado de pessoas a executarem diversas tarefas a fim de que o paciente seja retirado rapidamente dali, pressupondo ser o único momento em que há algo tecnicamente concreto a fazer.

Há de se considerar mais uma vez o caráter funcionalista da instituição pois onde há tarefas claras, pré-determinadas, elas são rapidamente assimiladas e cumpridas. Isto não ocorre quando o paciente vivencia sua terminalidade próxima, onde nada é claro, onde não há possibilidade de operacionalização de conteúdos ou de conceitos, onde é impossível determinar o que e como fazer.

Assim, para que os enfermeiros possam ajudar aos pacientes nesta circunstância, devem meditar sobre o que a morte representa para eles como indivíduos, e para aqueles que os rodeiam. Terá que desenvolver habilidades especiais de enf ermagem, se quiser atender devidamente aos enfermos nestes momentos. Faz-se necessário também que o enfermeiro seja capaz de reconhecer os sinais da morte eminente, para que possa atuar sem embaraço e consiga assistir integralmente ao paciente. 
Destaca-se que uma das habilidades fundamentais do enfermeiro que assiste ao paciente terminal é a comunicação. Há que encontrar um canal de comunicação, seja através da palavra escrita ou falada, da mímica ou através dos sentidos. Esta é uma das habilidades do enfermeiro que necessariamente transcende às técnicas.

\section{CONCLUSÕES}

Ao se apreciar obras que tratam de situações de vida e morte, chegou-se a algumas conclusões:

A morte é um fenômeno inalienável do homem. Entretanto, ele não a aceita como fazendo parte de sua existência. O seu inconsciente não a aceita. A experiência com a morte é o morrer do outro, e portanto, não vivenciada, em verdade, a morte.

O avanço científico e tecnológico que tomou conta do universo foi capaz de retardar a morte, entretanto, não conseguiu preparar meios que proporcionassem maior preparo ao homem para aceitá-la como fenômeno da existência.

Cinco são estágios que o homempassana suafase terminal de vida, segundo KUBLER-ROSS ${ }^{10}$, denominados de negação, ira, barganha, depressão e aceitação. Ėstes estágios não ocorrem necessariamente numa seqüência lógica, nem tampouco, todos os pacientes passam por todos eles. Estudos feitos por KUBLER-ROSS ${ }^{7}$ demonstraram que o homem é capaz de chegar à aceitação da sua morte, mas para tal, ele passa por fases de luta psicológica com a morte.
A equipe multiprofissional, segundo KUBLERROSS, não está preparada para ajudar o paciente na fase terminal, nem tampouco, para apoiar a família neste momento difícil. Pelo contrário, todos fogem, se negam a falar sobre o assunto. No máximo, cada profissional emite o seu parecer técnico. Percebe-se, mais uma vez, a ênfase que profissionais da saúde dão ao aspecto biológico em detrimento dos demais. Evidentemente que esta atitude não é isolada, esses profissionais são seres humanos e, sendo assim, têm seus medos, seus questionamentos acerca da morte. Como profissionais, entretanto, fica entendido que o enfermeiro deveria ser melhor preparado para ser capaz de manter uma relação interpessoal de ajuda que é a essência do ato de cuidar, tanto com o paciente terminal, quanto com seus familiares.

Vê-se que é essencial inserir nos currículos de graduação de enfermagem conteúdos filosóficos e sócio-antropológicos acerca da morte e não somente biológicos. O enfermeiro, sem sua formação acadêmica, é preparado para lidar com o corpo no pós-morte e portanto, ele não sabe como deverá se haver com as fases que antecedem o ato de morrer.

Estas questões deveriam fazer parte também das discussões sobre a prática profissional nas instituições de ensino, bem como assistenciais.

$\mathrm{O}$ assunto não se esgota aqui e é curioso observar em todas as obras lidas que a questão fundamental permanece: o que é exatamente a morte e o morrer?

\section{REFERÊNCIAS BIBLIOGRÁFICAS}

1 ARIES, Philippe. O homem diante da morte. Vol. I e II. Rio de Janeiro: Editora Francisco Alves, 1981.

2 BEATTIE, John. Introdução à Antropologia Social. 3ed. Rio de Janeiro: Editora Nacional, 1980.

3 BOEMER, Magali R. A morte e o morrer São Paulo: Ed Cortez, 1986.

4 BRUNNER, L.S. \& SUDDARTH, D.S. Enfermagem MédicoCirúrgica. 3ed, Rio de Janeiro: Interamericana, 1978.

5 Du GAS, B.W. Enfermagem prática. 3ed., Rio de Janeiro: Interamericana, 1978.

6 GELAIN, Ivo. Deontologia e Enfermagem. São Paulo: EPU, 1983.
7 GUIMARÃES, N.O. e col. Morte - um desafio de Enfermagem Fortaleza: XXXI CBEn, 1979.

8 MARANHÃO, José Luiz de Souza. O que é a morte São Paulo: Ed. Brasiliense, 1985.

9 RODRIGUES, José Carlos. Tabu do Corpo. Rio de Janeiro: Achiamé, 1979.

10 ROSS, Elisabeth Kubler. Sobre a morte e o morrer. 2. ed., São Paulo: Editora Martins Fontes, 1985.

11 Perguntas e respostas sobre a morte e o morrer São Paulo: Ed. Martins Fontes, 1979. 